\title{
THE SPINAL FLUID IN HYPERTENSION 1,2
}

\author{
By SAMUEL A. SHELBURNE, DANIEL BLAIN, and JAMES P. O'HARE
}

(From the Medical Clinic of the Peter Bent Brigham Hospital, Boston)

(Received for publication December 12, 1931)

This study was originally prompted by a very disturbing result of lumbar puncture in a patient who had headache, severe hypertensive disease and marked eyeground changes. Shortly after the puncture the patient became definitely psychotic. This brought to a head certain questions previously entertained concerning the intracranial pressure in this disease, how often the headache could be attributed to increased pressure within the skull, and when lumbar puncture could be used as a therapeutic measure.

We knew from the experience of others and our own earlier work that not every case of hypertension was accompanied by elevation of spinal fluid pressure. Our chief endeavor was to establish some method of determining which patients had such increased pressure without actually performing the lumbar puncture. If such an indirect method could be established, it would be possible often to avoid an unnecessary, troublesome and possibly harmful procedure.

Although many authors had written on this subject their conclusions were far from uniform. We will mention only a few papers to show the varying trend of ideas which confronted us in the literature. The earlier writers, notably Lyttkins (1), suggested on very scant evidence that a rise in blood pressure was followed by a rise in the cerebrospinal fluid pressure. Later work, principally by French investigators (2), seemed to demonstrate that there is no direct relationship between the pressures in the two systems. However, Claude and Lamache (2), Block and Oppenheimer (3), maintained that after an equilibrium has been established as in a patient with long standing hypertension, changes in the pressure of one system will be followed by similar changes in the other. From this it seemed fair to assume that an artificially produced reduction in the spinal fluid pressure might be followed by a fall in the blood pressure.

Previous investigators had made no effort to correlate the appearance of the optic disc, the clinical symptoms and the type of hypertension with the cerebrospinal fluid pressure. Larsson (4) studied the spinal fluid pressure of eleven patients who had choked discs associated with nephritis.

${ }^{1}$ Read before the American Society for Clinical Investigation, Atlantic City, May 4, 1931.

${ }^{2}$ Assisted by a Fund for the Study of Vascular and Renal Diseases. 
He found in all of his cases that papilledema was accompanied by an increased intracranial pressure. Fishberg and Oppenheimer (5), however, in their recent paper have suggested that the association of papilledema with increased cerebrospinal fluid pressure was not so constant as Larsson pointed out.

TABLE I

Findings on 22 cases of hypertensive disease that showed either edema of the discs or increased cerebrospinal fluid pressure*

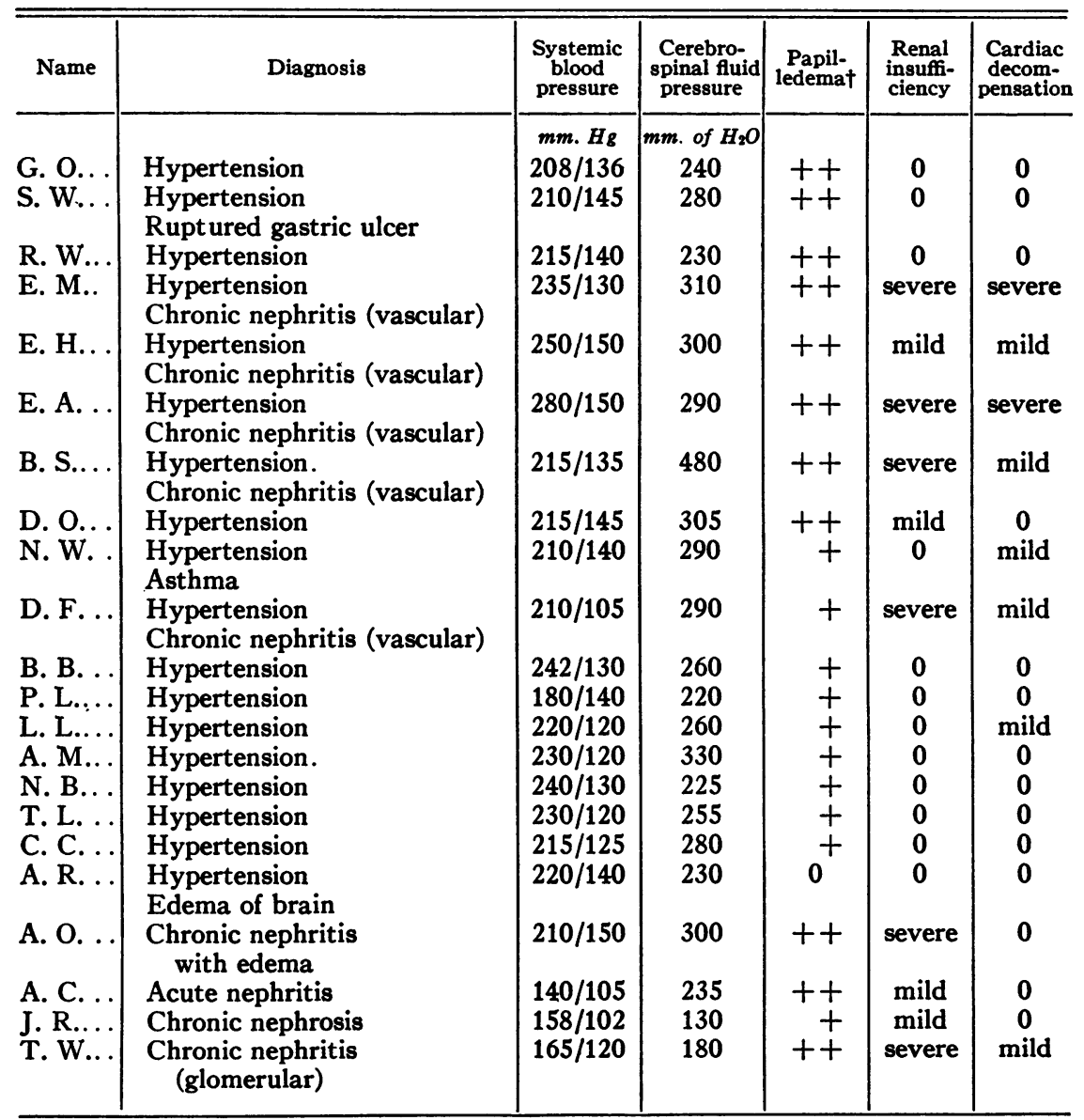

* The other 28 cases in this series are omitted for the sake of brevity. Although they were patients with hypertension, they showed neither edema of the disc nor increased cerebrospinal fluid pressure.

$\dagger+$ indicates physiological cup filled, indistinct disc margins, marked blurring of the disc but no elevation of the disc.

++ indicates definite elevation of the disc from 1 to 5 diopters (choking). 


\section{Method of StUdy}

Fifty patients with well marked hypertensive disease were selected. We avoided as far as possible cases with advanced cardiac congestive failure. Blood pressure readings had been made for several days before lumbar puncture was done. Readings were also made immediately before, during, and thirty to forty-five minutes after the puncture. Occasionally, another determination was made twelve hours later.

The lumbar punctures were made in the lateral recumbent position, exercising considerable care in "levelling" the patient. Water manometers were used and no reading was made until the oscillations accompanying the heart beat and respiration were stabilized. A reading of less than $200 \mathrm{~mm}$. was considered normal. In those patients with high intracranial pressures, care was exercised not to lower this pressure below $200 \mathrm{~mm}$. Cell counts, protein estimations, Wassermann and colloidal gold tests were made on all fluids. The results were normal. Chlorides were determined by the method of Whitehorn (10) in a sufficient number to indicate that these $\mathbf{5 0}$ were probably all normal.

Careful examination of the eyegrounds was made in every case. Roentgenograms of the skull were done in 32 cases. Renal function was determined by means of the phthalein test and the determination of the blood urea nitrogen.

The results of this study as a whole are outlined in Table I.

The relation of edema of the optic discs to the cerebrospinal fluid pressure is indicated in Table II.

TABLE II

Intraspinous pressure and papilledema

\begin{tabular}{|c|c|c|}
\hline \multicolumn{2}{|l|}{ Spinal fluid pressure } & With papilledema \\
\hline $\begin{array}{l}\text { Normal } \ldots \ldots \ldots \ldots \ldots \ldots \ldots \ldots \ldots \ldots \ldots \ldots \ldots \ldots \ldots \ldots \ldots \\
\text { Increased } \ldots \ldots \ldots \ldots \ldots \ldots \ldots \ldots\end{array}$ & $\begin{array}{c}\text { Number of cases } \\
30 \\
20\end{array}$ & $\begin{array}{c}\text { cases } \\
2 \\
19\end{array}$ \\
\hline
\end{tabular}

Out of 20 cases with increased spinal fluid pressure 19 disclosed papilledema. On the other hand, of the 30 with normal spinal pressures only 2 had papilledema. ${ }^{3}$

There were 4 cases which showed slight blurring of the discs with no filling of the physiological cup and no venous congestion. In all of these

${ }^{3}$ One of these two had the syndrome of nephrosis with early glomerulonephritis and while under our observation developed papilledema. Spinal fluid pressure was only $130 \mathrm{~mm}$. of water. The other had chronic glomerulonephritis with choking of both discs but spinal fluid pressure was $180 \mathrm{~mm}$. of water. This patient had a cellulitis in back of his left eye which may have contributed to the swelling of the nerve head 
the intracranial pressure was normal. These are not classed as true papilledema.

TABLE III

Papilledema and intraspinous pressure

Papilledema with no measurable choking............ 1 case $130 \mathrm{~mm}$.

7 cases $230 / 300 \mathrm{~mm}$.

1 case $330 \mathrm{~mm}$.

Papilledema with choking of one to five diopters.

1 case $180 \mathrm{~mm}$.

6 cases $230 / 300 \mathrm{~mm}$.

5 cases over $300 \mathrm{~mm}$.

Table III shows some correlation between the degree of papilledema and the intracranial pressure. The patients with mild papilledema as a rule had lower intracranial pressures than those with a greater degree of papilledema.

TABLE IV

Renal insufficiency

\begin{tabular}{|c|c|c|c|}
\hline \multicolumn{2}{|l|}{ Renal function } & \multicolumn{2}{|c|}{ Increase spinal pressure } \\
\hline $\begin{array}{l}\text { Normal } . . \ldots \ldots \ldots \ldots \ldots \ldots \ldots \ldots \\
\text { Depressed } \ldots \ldots \ldots \ldots \ldots \ldots \ldots\end{array}$ & $\begin{array}{c}\text { Number of cases } \\
34 \\
16\end{array}$ & $\begin{array}{c}\text { cases } \\
11 \\
10\end{array}$ & $\begin{array}{c}\text { per cent } \\
32 \\
63\end{array}$ \\
\hline
\end{tabular}

TABLE IV $a$

The relation of the degree of papilledema to the degree of renal impairment Papilledema

10 with less than 1 diopter choking $\ldots \ldots \ldots \ldots \ldots\left\{\begin{array}{l}8 \text { cases with normal function } \\ 1 \text { case with mild insufficiency } \\ 1 \text { case with marked insufficiency }\end{array}\right.$ 11 with 1 to 5 diopters choking. .............. $\left\{\begin{array}{l}3 \text { cases with normal function } \\ 3 \text { cases with mild insufficiency } \\ 5 \text { cases with marked insufficiency }\end{array}\right.$

In Table IV we see that papilledema occurred in 32 per cent of patients with normal renal function but in 66 per cent of those with impaired renal function. Moreover, in Table IVa we see that the degree of renal impairment is greater in those cases with more severe papilledema. In view of the work of Fishberg and Oppenheimer (5), Weiss and Ellis (6) and others we were not surprised at the high incidence of papilledema in those patients with hypertensive disease who have progressed to renal impairment. Of particular significance, however, is the fact that 11 patients with normal renal function had papilledema and increased intracranial pressure.

In Table $\mathrm{V}$ we see that headache occurs more frequently in those cases which have increased intracranial pressure and this at first suggests the pressure as a causative factor in the headache. But since 40 per cent 
TABLE V

Correlation of spinal fluid pressure with headaches

\begin{tabular}{c|c|c|c|c|c}
\hline \hline \multicolumn{2}{c|}{ Spinal fluid pressure } & \multicolumn{2}{|c|}{ Without headaches } & \multicolumn{2}{c}{ With headaches } \\
\cline { 2 - 6 } Normal.......... & Number of cases & cases & per cent & cases & per cent \\
Increased.......... & 30 & 18 & 60 & 12 & 40 \\
& 20 & 4 & 20 & 16 & 80 \\
\hline
\end{tabular}

of those with normal pressure also had headache, some other factor must certainly be present. It is possibly significant that 8 of the 12 with headache in the group with normal intracranial pressure had very high diastolic blood pressures.

Headache was relieved after lumbar puncture in only two cases and in three cases severe headaches followed the procedure. Cushing and Bordley (7) in 1908 reported temporary relief by subtemporal decompression of a partial blindness in a patient with chronic nephritis and choked discs. Larsson (4) showed a definite improvement in visual acuity in some of his cases on lumbar drainage. We studied two cases on the services of Dr. Cushing and Dr. O'Hare, who had marked diminution of visual acuity as a result of choked discs. Both had headaches and severe hypertensive vascular disease. The vision of one of these patients was relieved for about seven months following subtemporal decompression. The other had relief for a shorter period but died a few weeks after the decompression from ruptured peptic ulcer. It seems that while headache may be in part due to increased intracranial pressure, lumbar drainage for relief of headache is not justified. However, it appears from a study of Dr. Cushing's cases that subtemporal decompression in certain selected cases in the hands of a competent surgeon may be justified in the presence of advanced visual failure.

$$
\text { TABLE VI }
$$

Correlation of spinal fluid pressures with systolic and diastolic arterial pressures

\begin{tabular}{|c|c|c|c|c|c|c|c|}
\hline & & \multicolumn{6}{|c|}{ Blood pressures } \\
\hline \multirow{2}{*}{\multicolumn{2}{|c|}{ Spinal fluid pressure }} & \multicolumn{2}{|c|}{ Average } & \multirow{2}{*}{\multicolumn{2}{|c|}{$\begin{array}{c}\text { Number systolic } \\
\text { above 220 }\end{array}$}} & \multirow{2}{*}{\multicolumn{2}{|c|}{$\begin{array}{c}\text { Number diastolic } \\
\text { above } 130\end{array}$}} \\
\hline & & \multirow{2}{*}{$\begin{array}{l}\text { Systolic } \\
m m . H_{g}\end{array}$} & \multirow{2}{*}{$\frac{\text { Diastolic }}{m m . ~ H g}$} & & & & \\
\hline & $\begin{array}{l}\text { Number } \\
\text { of cases }\end{array}$ & & & cases & per cent & coses & per cent \\
\hline $\begin{array}{l}\text { Normal. . . . . . } \\
\text { Increased. . . . }\end{array}$ & $\begin{array}{l}30 \\
20\end{array}$ & $\begin{array}{l}198 \\
219\end{array}$ & $\begin{array}{l}115 \\
135\end{array}$ & $\begin{array}{r}10 \\
9\end{array}$ & $\begin{array}{l}33 \\
45\end{array}$ & $\begin{array}{r}8 \\
16\end{array}$ & $\begin{array}{l}31 \\
80\end{array}$ \\
\hline
\end{tabular}

The results shown in Table VI indicate that the average blood pressure, particularly the diastolic, is greater where spinal fluid pressure is increased. Sixteen out of 20 cases in this group had diastolic pressures 
over $130 \mathrm{~mm} . \mathrm{Hg}$. It is also important to note that 8 out of 30 in the group with normal spinal fluid pressure also had diastolic pressures over $130 \mathrm{~mm}$. Hg. We claim no direct causal relation but the frequency of high diastolic pressure is of interest. Weed and Hughson (8) from their work on animals believe there is no connection between the two.

A recent experiment by one of us (S. A. S.) at Lakeside Hospital in Cleveland is pertinent to this discussion. A patient with a right femoral arteriovenous fistula was studied. Occlusion of the fistula produced a rapid rise in the blood pressure, both systolic and diastolic. Chart I

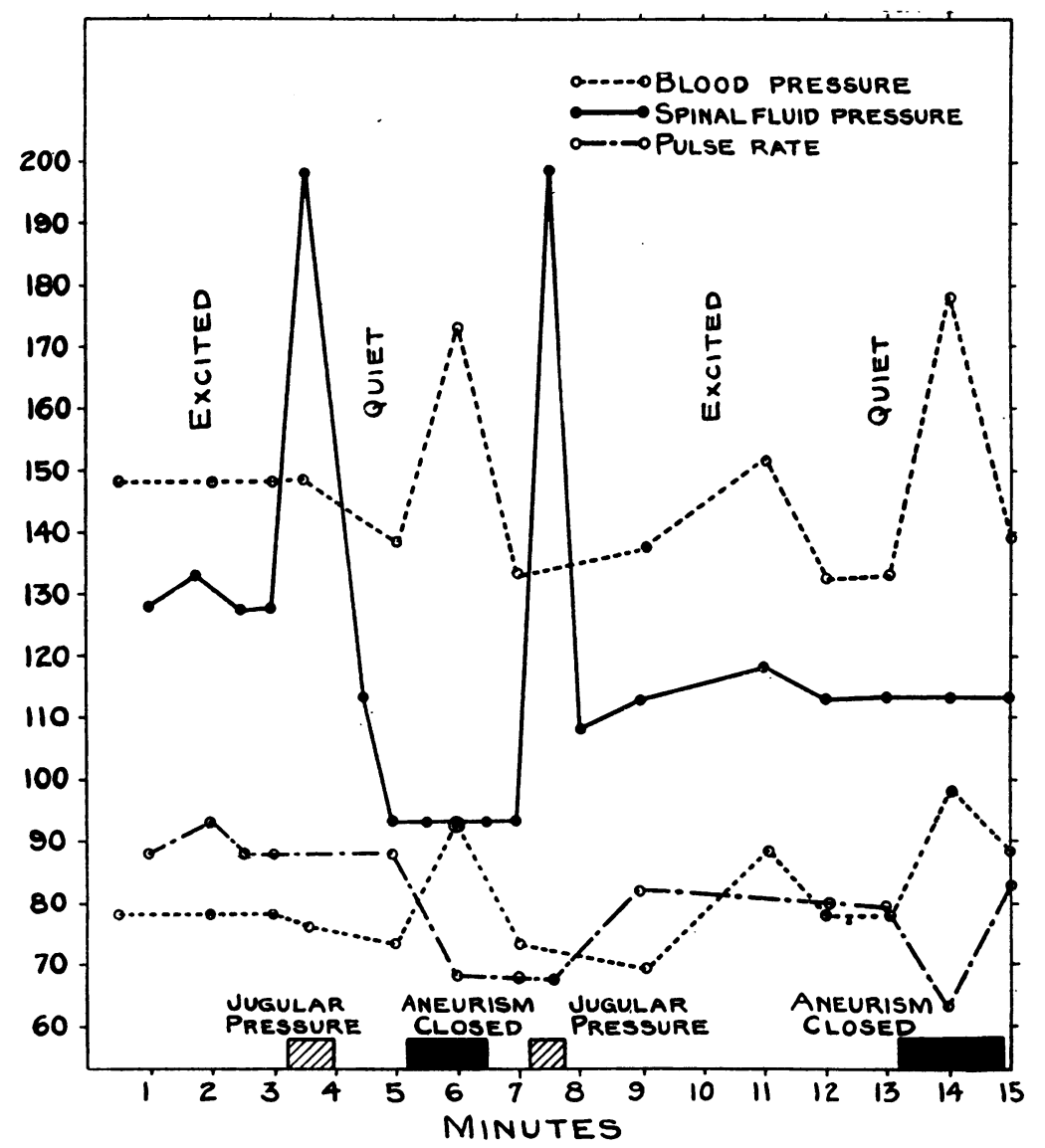

The Effect of Rapid Elevation of the Systemic Blood Pressure on the Spinal Fluid Pressure.

The elevation of the blood pressure is accomplished by the closure of a femoral arteriovenous aneurism.

shows the result of the studies of the spinal fluid pressures during the rise in blood pressure. We see here the typical rise in the spinal fluid pressure with jugular compression but no change during the rapid rise in arterial pressure. 
The records of the blood pressure changes during and after reduction of spinal fluid pressure show a fall of $15 \mathrm{~mm} . \mathrm{Hg}$ in either systolic or diastolic blood pressure in only 9 cases. Changes of less than $15 \mathrm{~mm}$. may be easily accounted for by the relief and relaxation which the patient experiences after the needle is in. (The blood pressure in a case of meningitis in coma was followed very carefully as the lumbar region was drained. The pressure of $140 / 70$ did not vary during the lowering of the spinal fluid pressure from $450 \mathrm{~mm}$. of water to $25 \mathrm{~mm}$.)

Roentgenological changes in the skull: $\mathrm{X}$-rays of the skull in 32 cases were made. Eleven of these had increased intracranial pressure as measured by the manometer but only 2 showed changes in the skull visible in $x$-ray. These signs were identical with those found with high intracranial pressures accompanying brain tumor.

In this short series of cases we can throw no light on the mechanism involved in the causation of increased intracranial pressure. Chemical studies of the fluid were negative throughout, one of two cases which came to autopsy showed edema of the brain, a majority of the increased pressures were accompanied by high arterial diastolic pressures, and there is a group of 7 cases which had neither chronic nephritis as a cause for choked disc, nor cardiac compensation with its associated increased venous pressure (6) (9).

\section{SUMMARY AND CONCLUSIONS}

1. A study of 50 cases of hypertensive disease showed 21 to have increased intracranial pressure.

2. Papilledema was almost always associated with increased intracranial pressure.

3. Papilledema and increased intracranial pressure occur more frequently with renal failure but are also found where renal function is normal.

4. Headache is more frequent in the presence of increased intracranial pressure and papilledema but occurs without either one. Our results indicate that lumbar drainage for relief of headache is not justified.

5. Increased intracranial pressure seems more often associated with high diastolic blood pressure but we feel that both are probably the result of some common factor and neither is caused by the other.

6. The cause of increased intracranial pressure is not accounted for in 50 per cent of our cases which have neither renal insufficiency nor increased venous pressure.

\section{BIBLIOGRAPHY}

1. Lyttkins, H.: Nord. med. Arch., 1918, 1, Avd.11, 207. Blood Pressure and Lumbar Pressure in 64 Cases of Disease of the Kidneys.

2. Claude, H., et Lamache, A., Compt. rend. Soc. de Biol., 1927, xcvi, 325, Relations entre la Pression Arterielle et la Tension Céphalorachidienne. 
3. Block, E. B., and Oppenheimer, R. H., Arch. Neurol. and Psychiat., 1924, xi, 444, A Comparative Study of Intraspinal Pressure, Blood Pressure and Intraocular Tension.

4. Larsson, S. W., Acta Ophth., 1923, i, 193, Choked Disc in Nephritis.

5. Fishberg A. M., and Oppenheimer, B. S., Arch. Int. Med., 1930, xlvi, 901, The Differentiation and Significance of Certain Ophthalmoscopic Pictures in Hypertensive Diseases.

6. Weiss, S., and Ellis, L. B., Am. Heart J., 1930, v, 448, The Quantitative Aspects and Dynamics of the Circulatory Mechanism in Arterial Hypertension.

7. Cushing, H., and Bordley, J., Jr., Am. J. Med. Sci., 1908, cxxxvi, 484, Subtemporal Decompression in a Case of Chronic Nephritis with Uremia.

8. Weed, L. H., and Hughson, W., Am. J. Physiol., 1921, lviii, 53, Systemic Effects of the Intravenous Injection of Solutions of Various Concentrations.

9. Eyster, J. A. E., The Clinical Aspects of Venous Pressure. The Macmillan Co., New York, 1929, p. 84.

10. Whitehorn, J. C., J. Biol. Chem., 1920-21, xlv, 449. A System of Blood Analysis. II. Simplified Method for the Determination of Chlorides in Blood or Plasma. 